\title{
LOS GLOSARIOS DE 1553 DE A. DE ULLOA
}

\author{
Lidio Nieto Jiménez \\ Instituto de Filología. CSIC
}

No es infrecuente encontrarnos con noticias u opiniones que se transmiten de unos a otros como seguras, cuando la verdad es muy otra. Este puede ser el caso de la referencia que Amado Alonso, probablemente el mejor conocedor de nuestro primer quehacer lingüístico, dedica a Alfonso de Ulloa en la reseña escrita a propósito del Tesoro lexicográfico de Samuel Gili Gaya ${ }^{1}$. Dice Amado Alonso que en su trato con gramáticas antiguas se ha encontrado con interesantes vocabularios que deberian tomarse en cuenta a la hora de fijar la historia de las palabras. Entre estos vocabularios menciona:

Alfonso de Ulloa: Introdutione del Signor Alphonso di Uglion nella quale s'insegna pronuntiare la lingua Spagnuola. Con una espositione da lui fatta nella Italiana di parecchi vocaboli Hispagnuoli dificili, contenuti quasi tutti nella Tragicomedia di Calisto e Melibea o Celestina, Vinegia, Gabriel Giolito, 1553, 28 folios en $8 .^{\circ}$. Está además incluido en la edición de la Celestina del mismo editor y año. (La Introdutione es un plagio descarado de la Introducción de Francisco Delicado, Venecia, 1533). Las palabras del vocabulario llegan casi a 900 . En el mismo año el mismo editor publicó el Orlando Furioso traducido por Jerónimo de Urrea, y Ulloa le adjuntó al final su Introdución..., con una exposición en la Thoscana de todos los vocablos difficultosos contenidos en el presente libro. No lo he podido ver, y dado el carácter trapisondista del caballero Ulloa, me temo que probablemente

1 Cfr. NRFH, V (1951), pág. 329.

Otras referencias del propio A. Alonso sobre Ulloa pueden encontrarse en su: De la pronunciación medieval a la moderna en español I, Madrid, Ed. Gredos, 2.* edic., 1967, págs. 345,113 n. 53 (aquí se nos dan datos biográficos), y 115 n. 55 .

La noticia, no obstante, más amplia que conozco de A. de Ulloa es la de Annamaria Gallina: Contributi alla storia della lessicografia italo-espagnola dei secoli XVI e XVII, Firenze, Leo S. Olschki Ed., 1959, págs. 59-71. La referencia en la misma a los glosarios que aquí analizo es más acertada que la de Amado Alonso, pero tampoco se ha detenido con profundidad en los mismos. 
sea en lo más repetición del vocabulario de la Celestina. Así, pues, resulta que el Vocabulario de LAS CaSAS, 1570, no es el primer español-italiano, si bien el de Ulloa no sea comparable por la extensión.

No entro a discutir las valoraciones del autor que hace Amado Alonso. Me limito a recordar cl texto, recogido, a su vez, por Homero Serís en la ficha núm. 12.508 de su Bibliografía de la lingüistica española, añadiendo: "Se publicó también en ed. independiente, Vinegia, 1553, 28 folios, y luego se incorporó a la citada ed. de la Celestina".

En mi elaboración del Nuevo Tesoro lexicográfico español he tenido necesidad de revisar los dos vocabularios aludidos y creo que el temor de Amado Alonso carece de fundamento, por múltiples razones. Enunciaré en este momento solamente dos: la escasa coincidencia de las voces explicadas en los dos glosarios, y la distinta manera de enfocar la explicación. Volveré luego sobre estas razones.

Quisiera aclarar antes que cronológicamente el glosario del Orlando Furioso es anterior al de la Celestina. Esto se deduce fácilmente de las palabras que el propio Alfonso de Ulloa dirige al lector al comienzo del primero de los libros, justificando su labor y saliendo al paso de los críticos: "Esto se ha hecho y dicho por utilidad y defensión del libro, porque sé que a la nueua adición no faltaran maldizientes, y para rogar al lector que con buen amor y caridad resciba lo que el señor don Hieronimo le da del fructo del talento que le fue encomendado, entre tanto que se le dará presto la Tragicomedia de Calisto y Melibea, con nueua inuención impressa y con diligencia corregida por mi". Es decir, el glosario que aparece en el Orlando Furioso no puede ser repetición del que encontramos en la Celestina; en todo caso, al revés.

La verdad es que, en mi opinión, y como decía antes, hay entre ambos $\tan$ escasa coincidencia de voces explicadas y tan distinta forma de encarar la explicación que me atrevo a proclamar la total independencia de uno y otro. Cosa distinta es la posible coincidencia en fuentes. Me refiero a fuentes mediatas, porque la fuente más importante y cercana son los textos a los que sirven los glosarios en cuestión y aquí, insisto, hay independencia. La coincidencia, pues, yo la veo en la utilización del Vocabulario de Nebrija para fijar significados y establecer la equivalencia latina de no pocas voces.

Que Ulloa recurre a Nebrija en numerosas ocasiones tanto en el glosario del Orlando como en el de la Celestina, me parece evidente. Por un lado, porque él mismo afirma a propósito de la voz marrano (glosario del Orlando): "Propriamente appresso gli hispagnuoli è compreso per un porco d'uno anno; questo afferma il dotto Antonio Nebriscia nel suo dictionario" 2 . Por otra

2 Efectivamente, Nebrija define la voz marrano como: «cochino de año; maialis, -is». 
parte, porque basta contrastar las explicaciones de Ulloa con las definiciones de Nebrija para darse cuenta del paralelismo existente entre ambos autores. Tomemos algunos ejemplos:

$$
\text { UlLoA (Orlando F.) }
$$

Arremetida (s. v. arremetía fiero)... inuasio et impetus appresso i latini e detto.

Ancas... appo i lattini e detto coxendis.

Alarde... latinamente detto recensio.

Buril... i latini lo chiamamo caestrum.

Çurrón... appreso i latini pera et follicus uien detto.

Colmillos... appreso i latini detti dentes culumeilaris.

Cosso... latinamente harena.

Comedimento... appo i latini praemeditatio.

\section{Nebrija}

Arremetida: invasio, -onis, impetus, -us.

Anca donde juegan los uesos: coxendix. Alarde de gente: recensio; rccensus, -us. Buril para labrar marfil: cestrum.

Çurrón: pera, -ae; folliculus, -i.

Colmillo: dens columellaris.

Cosso do corren el toro: harena, -ae.

Comedimiento: praemeditatio, -onis.

Como el glosario de la Celestina sigue un planteamiento diferente: enunciación del término castellano que se quiere explicar, en una columna, y en la siguiente el equivalente italiano, las conexiones con Nebrija aparecen como explicaciones complementarias, también muy concretas. Veamos algunos casos, en cuanto esquema repetido en todo el glosario.

\section{UlLoA (Celestina)}

Descalabrados: per excerebratum, con voce latina.

Descalabradura: per excerebratio, appo i latini.

Dentera bauer en ellos: per stupend dentes, appreso $i$ latini.

Enconar la llaga: per ulcero, con uoce latina.

Enconamiento assi: per exulceratio, con uoce latina.

Enterrar otra cosa: per infodio, appo i latini.

Enterramiento assí: per infossionis con uoce latina.

\section{Nebrija}

Descalabrado: excerebratus, -a, -um.

Descalabradura: excerebratio, onis.

Dentera aver en ellos: stupend dentes.

Enconar la llaga: ulcero, as; exulcero, -as.

Enconamiento assi: exulceratio, -onis.

Enterrar otra cosa: infodio, -is; defodio, -is.

Enterramiento assi: infossio, defossio. 
Al margen, insisto, de esta coincidencia en una fuente mediata, los glosarios comentados de Alfonso de Ulloa tienen poco en común. Su planta es totalmente diferente, salvo el hecho de la ordenación alfabética; pero mientras que el glosario de la Celestina se limita a establecer la estricta correspondencia español-italiano en dos columnas y término a término, el del Orlando Furioso reduce el número de entradas, con remisión precisa de éstas a pág., columna, etc. del texto explicado. Por otra parte, coloca bajo cada entrada agrupamientos léxicos de muy diversa índole, cuya ligazón entre ellos y con respecto al tema de entrada es variable. Así, mientras aparecen familias bastante completas: azeyte, azeytera, azeitero, azeitoso, azeituno (árbol), azeituna, hay otros agrupamientos que guardan entre sí una relativa relación: azebo, azebuche, azebuchar (sí los dos últimos, pero no con el primero, excepto cierta coincidencia de significante) o prácticamente ninguna, como ocurre con los términos que se incluyen bajo el lema jaula, excepción hecha del primero de ellos: jaulero, jauali, jornalero, junco, justa, juramento, jarro, juiego. Algo parecido pasa con calle, recogida bajo la voz callado, y que sólo por proximidad fonética tiene explicación.

Los agrupamientos derivativos son, lógicamente, los más frecuentes. Pero junto a ejemplos como apercebir, apercebimiento, apercebido; aposentar (se), aposentador, aposento, aposcntado; casar(se), casamiento, casamentero, casado, y otros muchos, cabe mencionar: a) los que el derivado es un colectivo: parra-parral, şarça-şarçal, enzina-enzinal, manşana-mançanal; b) aquellos otros en los que teniendo también valor sustantivo el derivado lo que destaca es su carácter activo, de acuerdo con la idiosincrasia del sufijo -ero: olla - ollero, jaula - jaulero, uenta - uentero, mesón-mesonero, ganadoganadero, lisonja-lisonjero; c) hay otros derivados: entrañas-entrañable, barriga - barrigudo, bullicio - bullicioso, cumbre - encumbrado, alevoso - alevosía, etc. que responden a criterios diversos.

Es frecuente el registro y posterior explicación de palabras polisémicas, con idéntico o diverso origen etimológico: sierra ('montaña' 'instrumento para cortar hierro'), era ('cómputo cronológico' 'lugar donde se trilla' 'espacio reservado para un cultivo'), corte ('el corte de un traje' $\sim$ 'la corte del rey'), rodilla ('parte de la pierna' 'paño de limpieza de cocina'), cuerda ('instrumento para atar' $\sim$ 'persona sensata'), canto ('piedra' $\sim$ 'acción y efecto de cantar'), calçada ('vía, camino' 'persona con calzas'), etc. Estas explicaciones suelen insertarse en conjuntos léxicos más amplios; por ejemplo, canto aparece bajo la voz cantos, doncle también se registran cantero, guijarro y cantería ; corte se encuentra bajo la entrada cortadora, que, a su vez, agrupa cortar y la forma de gerundio cortando, forma que, al igual que otras verbales, excepción hecha del participio, por su valor adjetival, no ha sido tenida en cuenta en el glosario que reproduzco. 
No falta tampoco la mención por sinonimia o cuasi sinonimia : raposozorra, mojón - linde, establo - caualleriza, cueua - cauerna, cordero-borrego, adarue - cerca, uenta - mesón. Es la cuasi sinonimia, entiendo, la que empuja a matizaciones semánticas: cauerna 'cueua larga y obscura'; uenta 'propiamente la que está junto al camino'.

Llama, por último, la atención cómo se destaca la variación semántica que la conversión pronominal de algunos verbos puede llevar consigo: alçar 'levantar lo caido', frente a alçarse 'soliviantarse'; despedir 'alejar de sí a uno', frente a despedirse 'decir adiós'.

Además de la divergencia de planta, los glosarios comentados coinciden ligeramente en sus registros léxicos. Para objetivar más esta afirmación, y al mismo tiempo con el deseo de ofrecer a los investigadores de la historia del español unos repertorios lexicográficos que anticipan en muchos casos la datación conocida de algunas palabras, presento los dos vocabularios enfrentados, advirtiendo:

A) en cuanto al correspondiente a la edición del Orlando:

$\left.1 .^{\circ}\right)$ que corrijo la planta original y presento un listado alfabetizado de las voces cuyo significado se explica. Dada, por otra parte, la dificultad que tiene la localización de un término en el original, al no estar ordenado alfabéticamente, en aquellas voces que no son entrada hago figurar ésta entre paréntesis, por ej., acontescimiento (s. v. acontescido).

2..$^{\circ}$ En este mismo glosario hay verbos que se mencionan en forma transitiva y pronominal (alabar $\sim$ alabarse). Cuando esto ocurre, para no alargar los listados, tras el infinitivo aparece entre paréntesis el pronombre se: aguijar(se).

3. ${ }^{\circ}$ Todas las formas personales mencionadas, aunque fueren entradas, se reducen a su correspondiente infinitivo. Se exceptúa el participio, por su valor adjetival. En todo caso, éste se recoge indistintamente en su forma masculina o femenina.

$4^{\circ}$ ) Cuando una voz aparece recogida en dos o más lugares también se señala: amarrar (s. v. desamarrar y atado).

B) por lo que se refiere al glosario de la Celestina:

$\left.1 .^{\circ}\right)$ Corrijo la ordenación alfabética del original.

$2^{\circ}{ }^{\circ}$ Prescindo en los verbos de toda forma que no sea el infinitivo (excepción hecha del participio), siempre que esté recogido en 
éste el significado de esas formas que se eliminan; por ej., nada se añade al registrar abastando cuando su significado está recogido en abastar.

3..$^{\circ}$ Prescindo también de las formas plurales cuando se menciona el singular; asi, por ej., elimino abastecidos porque se registra abastecido con igual significado.

4..$^{\circ}$ Como norma general se eliminan las formas repetidas que no aportan significados diferentes. Si se mantienen, en cambio, las voces diferentes que tienen igual significado; por ej., abasto y abastança. Se mantienen igualmente las voces o sintagmas que ofrecen matices semánticos: alcançar, alcançar lo que huye, alcansar lo desseado, etc.

Quiero aclarar que mi objetivo no es el estudio pormenorizado del léxico aquí ofrecido, sino el simple repertorio del que partir para ese tipo de trahajos. Al enfrentar los glosarios de A. de Ulloa me encuentro con que normalmente no hay correspondencia y entonces lo señalo con un guión (-) en la columna correspondiente. En otros casos una única forma corresponde a dos o más del otro glosario y lo indico repitiendo la forma primera (con comillas). Quiere ello decir que para establecer la correspondencia he tenido en cuenta la traducción italiana que hace el autor. Insisto, no obstante, en que sin entrar excesivamente en matizaciones.

Teniendo en cuenta que estos glosarios se anticipan en bastantes años al Vocabulario de las dos lenguas toscana y castellana de Cristóbal de las Casas, considerado tradicionalmente el primer diccionario español-italiano, he hecho un pequeño sondeo para tratar de descubrir el grado de relación existente entre unos y otro. A la vista de mi comprohación, pienso que las Casas no tuvo en cuenta, o lo hizo de manera muy superficial, los repertorios de Ulloa. Y ello por dos razones: primero, porque son bastantes las voces de los glosarios de Ulloa no recogidas en el Vocabulario de las Casas; y segundo, porque algunas de las no recogidas son muy significativas (adarve, aludas, etc.) y por lo mismo no le hubieran pasado desapercibidas.

Para terminar, creo que no se puede decir que los glosarios aquí recogidos no tengan nada en común, porque es evidente, cuando hay correspondencia de voces, que en muchos casos el de la Celestina repite las matizaciones semánticas contempladas en el del Orlando. Pero, en conjunto, entiendo que se trata de dos glosarios diferentes, que responden cada uno a un objetivo concreto. 


\begin{tabular}{|c|c|}
\hline - & Abasta \\
\hline - & abastança \\
\hline - & abastar \\
\hline- & abastecido \\
\hline - & abasto \\
\hline- & abaxamiento \\
\hline- & abaxar otra cosa de alto \\
\hline- & abaxar o descender \\
\hline- & abaxar lo soberuio \\
\hline- & abbades prelados \\
\hline- & abbades o clérigos \\
\hline abejas & abeja animalico \\
\hline abollado (s.v. abollar) & - \\
\hline abollar & - \\
\hline abrasada (s. v. brasa) & - \\
\hline abrigado (s. v. abrigo) & - \\
\hline abrigo & - \\
\hline acabar & - \\
\hline - & açadón de cauar \\
\hline acatar & acatar \\
\hline$"$ & acatamiento tener \\
\hline$"$ & acatamiento de Dios \\
\hline$"$ & acatamiento tuyo \\
\hline acaudillada & - \\
\hline- & achacados \\
\hline - & achacar algo \\
\hline acontescer (s.v. acontescido) & - \\
\hline acontescido & - \\
\hline acontescimiento (s. v. acontescido) & - \\
\hline acostada & - \\
\hline acostamiento (s.v. acostada) & - \\
\hline acostarse (s. v. acostada) & - \\
\hline- & açotado \\
\hline acotar (s. v. coto) & - \\
\hline - & açotea \\
\hline - & açotes \\
\hline acudamiento (s. v. acudir) & - \\
\hline acudir & - \\
\hline acuestas & - \\
\hline adarue & adarues o cercas \\
\hline adereços (s.v. aderesçados) & - \\
\hline aderesçados & - \\
\hline aderesçadura (s. v. aderesçados) & - \\
\hline adeuinado & - \\
\hline adeuinar (s. v. adeuinado) & - \\
\hline
\end{tabular}


,

"

,

$-$

$-$

alçar(se)

alcayde

$-$

-

-

aldea

aldeano (s. v. aldea)

aleuosía (s.v. aleuoso)

aleuoso

alexar(se)

algo

algodón

alhombras (y s. v. arraibanas)

alhuzema (s.v. arraihanas)

aliento (s.v. buelgo)

aliuiar

allegada

一

-

-

allende

-

almenas

almirez (s.v. alhombras)

almohada (s.v. arraibanas)

(véase atramuces)

aludas

al[ tino]

ama

"

amador (s.v. amantes)

-

amantes

amanzillada (s.v. amanzillar)

amanzillar

amar (s. v. amantes)

amarillo

amarrar (s. v. desamarrar y atado) alcançar lo alto

alcançar al que camina

alcançar lo desseado

alcançar lo que huye

alcance de lo que huye

alcandera de halcones

alcanderas o perchas

-

alchacar algo

alchueta

alçofaifas

alcoholarse la muger

-

aleuosía destos

aleuosos

algo aduerbio

algodones

-

aliento

$-$

allegamiento assí

allegar o arriuar al lugar

allegar ayuntando

allegarse al señor

almazén no gastar [?]

-

almohaça

altramuzes

ama muger déste

ama muger que cría hijo ageno

amagar queriendo dar

amanesce

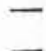

$-$

amarillo 
amedrentados

amedrentar (s. v. amedrentados)

$\bar{\Xi}$
$\bar{\Xi}$

amontonar (s. v. montones)

amparo (s. v. desamparada)

ancas

ancha

anchura (s. v. ancha)

ancianidad (s. v. anciano)

anciano

-

andas

$-$

$\overline{-}$

antojadizo (s. v. antojo)

antojo

anzuelo

apartamiento (s.v. apartar)

apartar(se)

apear(se)

apercebido

apercebimientos (s.v. apercebido)

apercebir(se) (s. v. apercebido)

aposentado

aposentador (s. v. aposentado)

aposentarse (s.v. aposentado)

aposento (s. v. aposentado)

apressurada

apressuradamente (s.v. apressurada)

apretado (s. v. aprieto)

apretar (s.v. aprieto)

aprieto

$-$

arbejas

arberjar (s.v. arbejas)

argolla

arraihanas

arrancadura (s. v. arrancar)

arrancar

arrastrado (s. v. arrastrar)

arrastrar

arrauales

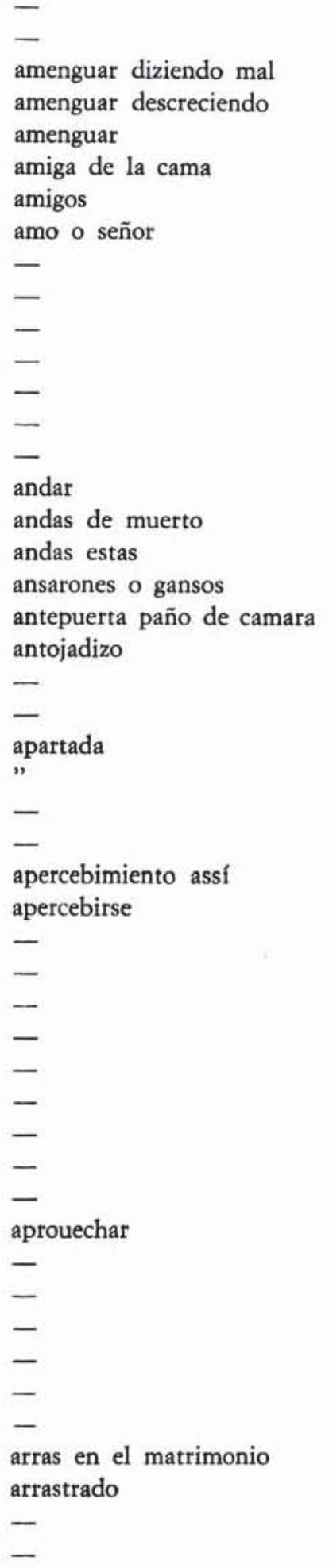




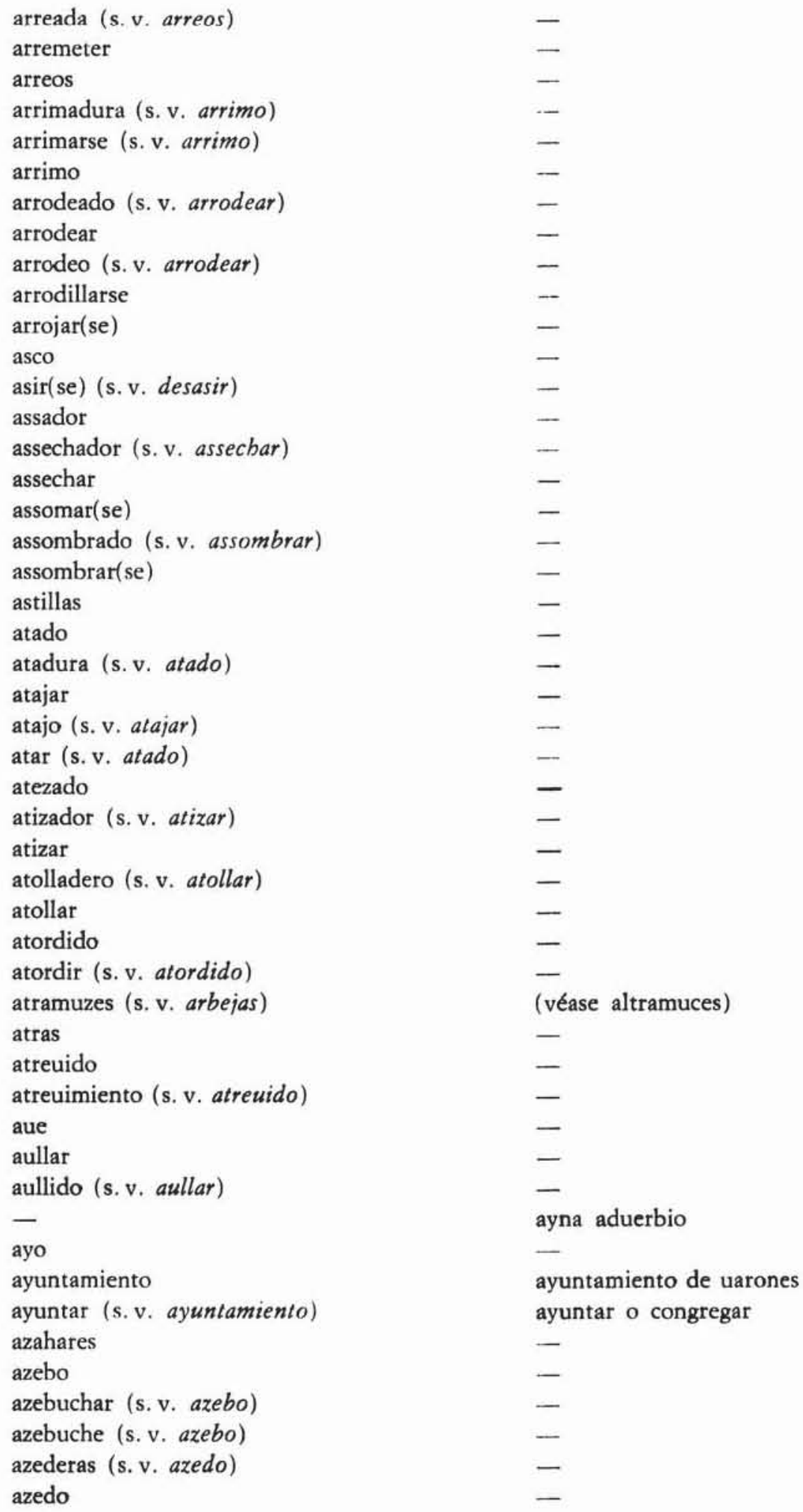

ayna aduerbio

ayuntamiento de uarones ayuntar o congregar 
azeitero (s.v. azeyte)

azeitoso (s. v. azeyte)

azeituna (s. v. azeyte)

azeituno (s.v. azeyte)

azeyte

azeytera (s. v. azeyte)

azul

-

-

baraja

barajar (s.v. baraja)

barrenar (s.v. barreno)

barreno

barreras

barriga

barrigudo (s, v, barriga)

一

barro

barroso (s.v. barro)

-

baxillas

beodo (s. v. borracho)

-

boçal mancebo

boda

-

-

bordadas

bordador (s. v. bordadas)

bordaduras (s. v. bordadas)

bordar (s. v. bordadas)

borde

-

borracho

borregos (s. v. cordero)

-
-
-
braçalete
bramar
brasa

-
-
-
-
-

badajo hombre balar el ganado baldón

baldonar

一

barrancos

-

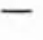

$-$

-

barrios

$-$

-

barruntar

barrunte

(véase borracho o beodo)

bienauenturadamente

bienes o hazienda

boçal mancebo

bodas

bodegón o tauerna

bodigo de offrenda

boffetada

boffetón

-

-

$-$

borrachería o imbriguez

boracho o beodo

(véase cordero o borrego)

bote de conserua

boticario

boua

bouería désta

- 
buelcos

buhos

bullicio (s.v. bullicioso)

bulliciones (s. v. bullicioso)

bullicioso

buril

cabe

一

cabeçones

caber (s.v. cabe)

-

一

-

-

calçada

calças (s.v. calçada)

-

calentura

callado

callar (s.v. callado)

calle (s.v. callado)

callejas

callejón (s.v. callejas)

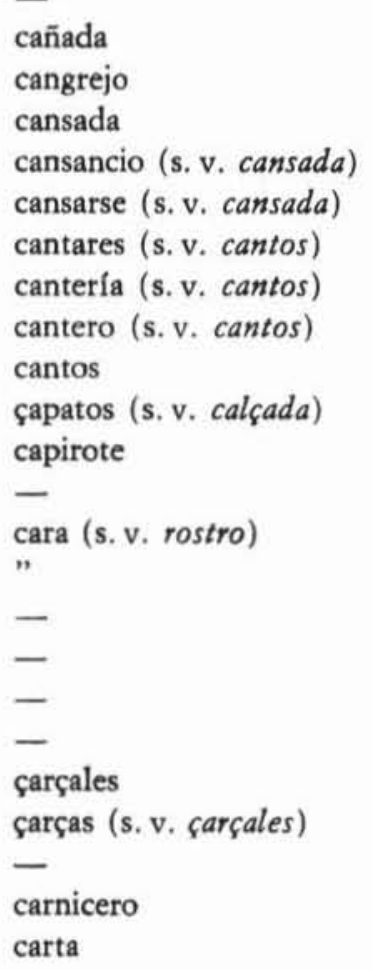

buena dicha

buho

-

$\overline{-}$

-

cabeça

-

cabrillas constellación

cabrón para casta

cacarear el gallo

caduco uarón

caer

-

calderón

-

callar

-

-

cama o lecho

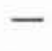

cansado

cansancio

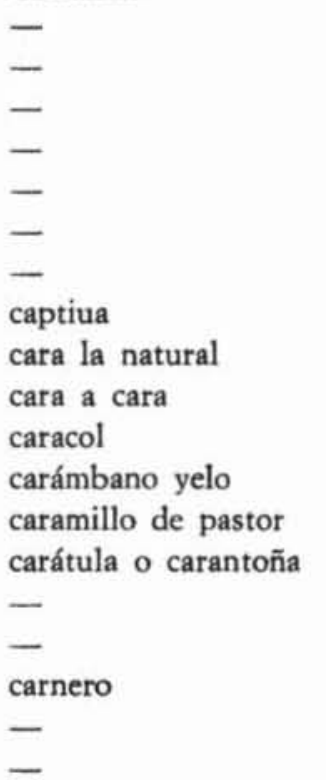


cartearse (s. v, carta)

casado (s.v. casamiento)

casamentero (s. v. casamiento)

casamiento

casarse (s.v. casamiento)

caualleriza (s. v. establo)

caudillo

cauerna (s. v. cueva)

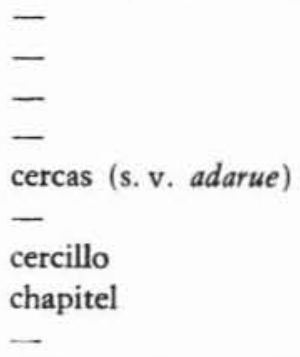

chismero (s.v. parlero)

chufar (s. v. chuferia)

chufas (s.v. chuferia)

chufería

cobijado

-

-

colgada

colmena (y s. v. abejas)

colmenar (s.v. colmena)

colmenero (osso s. v. colmena)

colmillos

comedido (s. v. comedimiento)

comedimiento

concertado (s. v. concierto)

concertarse (s. v. concierto)

concierto

-

conseja

contender (s. v. contienda)

contienda

copos

coraçón

cordel

cordero

cordura

corneja

$$
\begin{aligned}
& \text { casados } \\
& - \\
& - \\
& \text { - } \\
& \text { cata que } \\
& \text { - } \\
& \text { - } \\
& \text { caxa de anillos } \\
& \text { caxuela } \\
& \text { ceñidero } \\
& \text { centeno } \\
& \text { cerca al derredor } \\
& \text { cerca preposición } \\
& \text { - } \\
& \text { - } \\
& \text { charcos de agua } \\
& \text { - } \\
& \text { - } \\
& \text { - } \\
& \text { - } \\
& \text { cobarde } \\
& \text { - } \\
& \text { cobrar la deuda } \\
& \text { cobrar lo perdido } \\
& \text { codornizes } \\
& \text { - } \\
& \text { - } \\
& \text { - } \\
& \text { - } \\
& \text { - } \\
& \text { - } \\
& \text { conmónón } \\
& \text { - } \\
& \hline \\
& \hline
\end{aligned}
$$




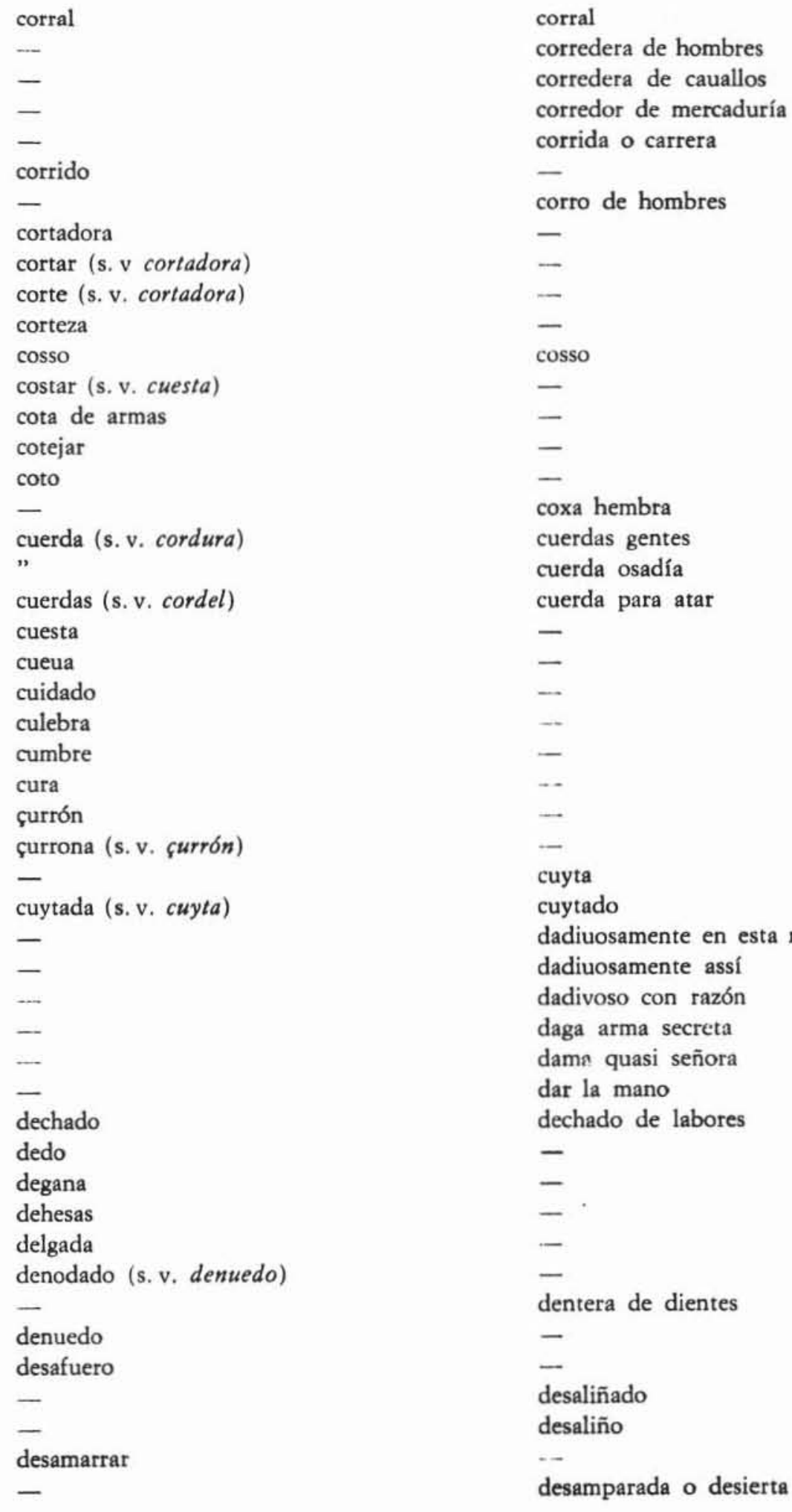

corral corredera de hombres corredera de cauallos corredor de mercaduría corrida o carrera

corro de hombres 
desamparada

desamparar (s.v. desamparada)

-

desasir(se)

-

$\overline{-}$

$-$

desatinar (s. v. tino)

-

$\overline{-}$

-

descansar (s.v. descanso)

descanso

descobijado (s.v. cobijado)

descomedido (s v. comedimiento)

-

desmandado

-

despedido

despedir(se) (s.v. despedido)

"

$-$

despeñarse ( $\mathrm{s}$ v. peñoso)

-

despertador (reloj; s.v. despertar) despertar

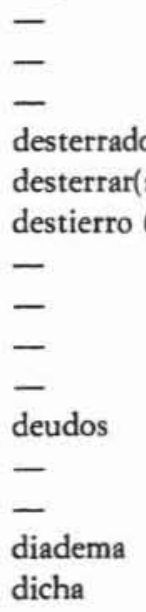

-

desamparar

desamparo de persona o lugar

desastrado

desastre

desatacados

desatacar

desatinar

desatino (v. tino)

descabullirse

descalabrados

descalabradura

descansado

descanso

-

desechar

desenterrar muerto

-

desmayar

desmayo

despedida de aqueste

despedir el capitán la gente

despedir al que sirue

despedirse

despeñadero

despeñado

-

despenseros

-

despertarse

despierto

dessabrida

dessabrido sin sabor

$-$

-

desuariado

desuario

desuenturadas

deuaneo

deudo o pariente

dexar por cessar

dexar

dicha buena

dicho 


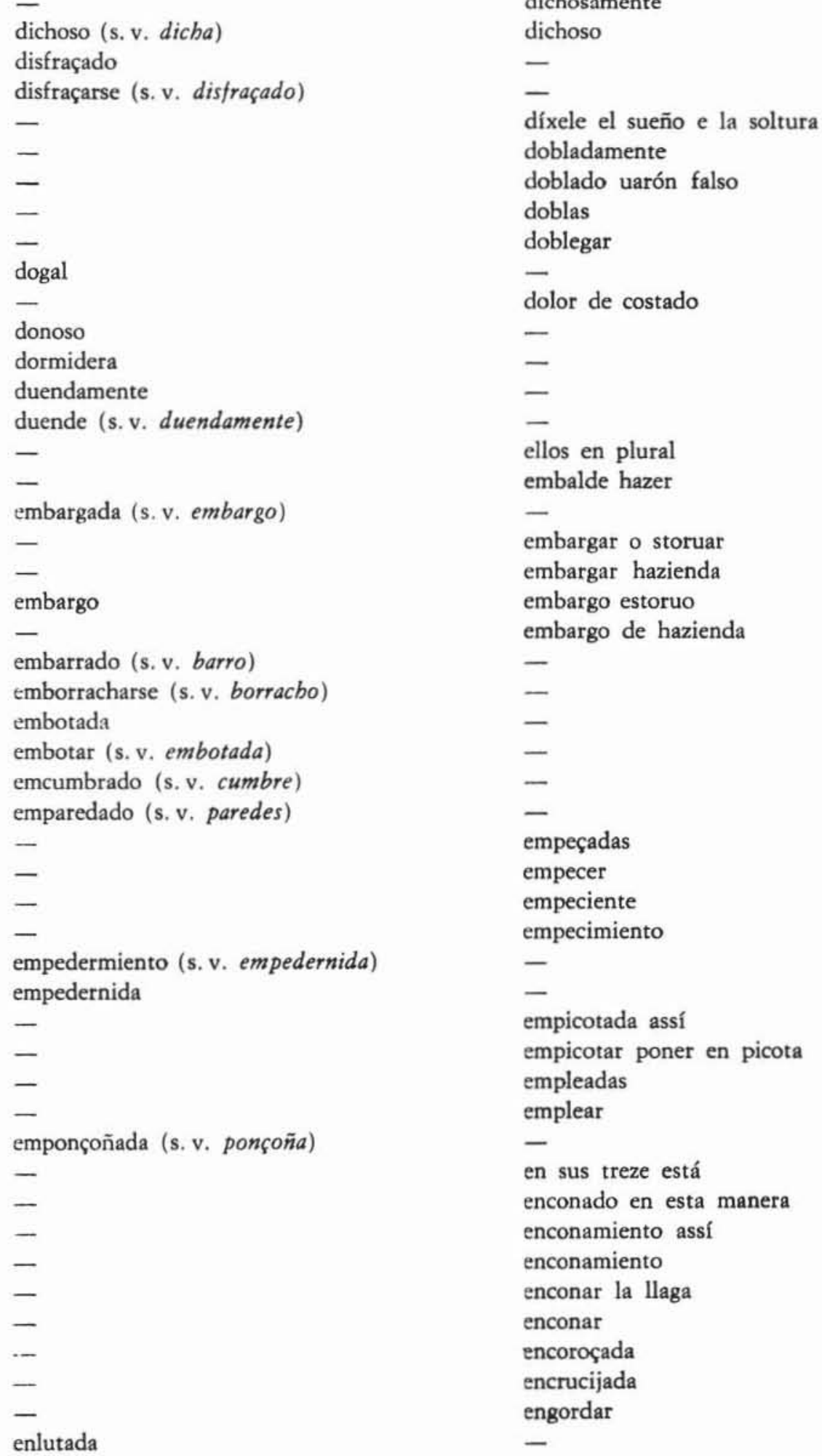


enojados

enojar(se) (s. v. enojados)

enojo yra que se dura (s.v. enojados)

enojo yra súpita (s.v. enojados)

enojo (s.v. enojados)

enojoso (s. v. enojados)

-
-
-
-
-
-

(véase estonces)

entrañable (s. v. entrañas)

entrañas

entregar

enzin

enzinal (s. v. enzina)

era

escamochos

-

escarmentar

escoger (s. v. escogidisimo)

escogidísimo

-

esforçado (s. v. fuerça)

-

-

-

-

esquadra (s v. quadrilla)

establo

-

estonces

estoruo (s. v. embargo)

-

estribo

-

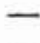

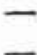

enojado en esta manera

enojar a otro

enojo ira que dura

enojo ira súpita

enojo en esta manera

enojoso a otro

enruuiar(se)

ensañadamente

ensañarse

enterramiento assí

enterramiento de muchus

enterramiento lugar

enterramiento

enterrar otra cosa

entonces

entrañas

enués

-

$-$

escardilla

escarmentar en cabeça agena

escarmiento os será ésto

escoger como quiera

escogido entre muchos

escogimiento assí

esgarrochados

eslauón de sacar fuego

eslauones de cadena

espulgar piojos

espulgar el negocio

estambre

estantigua

(véase entonces)

estrado de almohadas

estrado

estudiantes

faldriquera

falla por falta

fallar por faltar

falta por mengua 


\begin{tabular}{|c|c|}
\hline- & falta por culpa \\
\hline - & faltar \\
\hline - & faltosa cosa que falta \\
\hline fealdad (s. v. feo) & fealdad \\
\hline - & fea cosa \\
\hline feo & fea cosa deshonesta \\
\hline - & feligrés \\
\hline - & finado o muerto \\
\hline - & final cosa \\
\hline - & fingido amigo \\
\hline - & fingimiento \\
\hline - & flaca cosa assí \\
\hline 一 & flaca cosa doliente \\
\hline - & flaca cosa magra \\
\hline - & flaca cosa quebradera \\
\hline - & flaca cosa sin fuerças \\
\hline - & flaco que no se puede tener \\
\hline - & flaco por no poder combattir \\
\hline - & flaqueza del que no se tiene \\
\hline - & flaqueza o magreza \\
\hline flota & - \\
\hline fragua & 一 \\
\hline fuerça & - \\
\hline fuero & - \\
\hline - & fuzia o confiança \\
\hline gaçapo & - \\
\hline gaitas & - \\
\hline 一 & galanes \\
\hline galápago & - \\
\hline - & gamones \\
\hline ganadero (s. v. ganado) & ganadero destos \\
\hline ganado & ganados bienes \\
\hline$"$ & ganados o greyes \\
\hline - & ganancia \\
\hline - & ganapán \\
\hline - & gargajo \\
\hline - & garganta o gorja \\
\hline - & gargantón \\
\hline - & garridamente \\
\hline - & garrido \\
\hline garrochado & - \\
\hline garrochar (s.v. garrocbado) & 一 \\
\hline garrochas (s.v. garrochado) & garrocha \\
\hline gastador (s. v. gastar) & - \\
\hline gastar & - \\
\hline- & gayta \\
\hline gesto & gesto con uisage \\
\hline$"$ & gesto la cara \\
\hline- & gloria uana \\
\hline
\end{tabular}




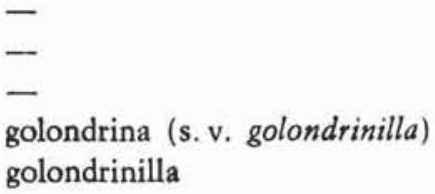

gloria uerdadera

gloria

gloriarse

-

gorda cossa

gordo madero o gruesso

gordura

gozar de lo desseado

gozar los años

gozar de algo como de fin

gozarse

gozo como quiera

gozoso assí

guarda la persona que guarda

guarda lugar donde guardamos

guarda el mismo que guardar

guardador o escasso

guardar como quiera

guardar en lugar

guardar hazienda

guardarse

guardo desta manera

-

gusanienta cosa

gusano commún

habla desta manera

hablador de nouellas

hablar consejas o nouelas

hablar naturalmente

hablar entre dientes

hablillas

hacha de armas

hacha que corta

hacha de cera

halagar

-

haldas de uestidura

haldura cosa con haldas

hartarse comiendo

hartar con hastío

harto quedo

hartura can hastío

harto

harto y en hastío 


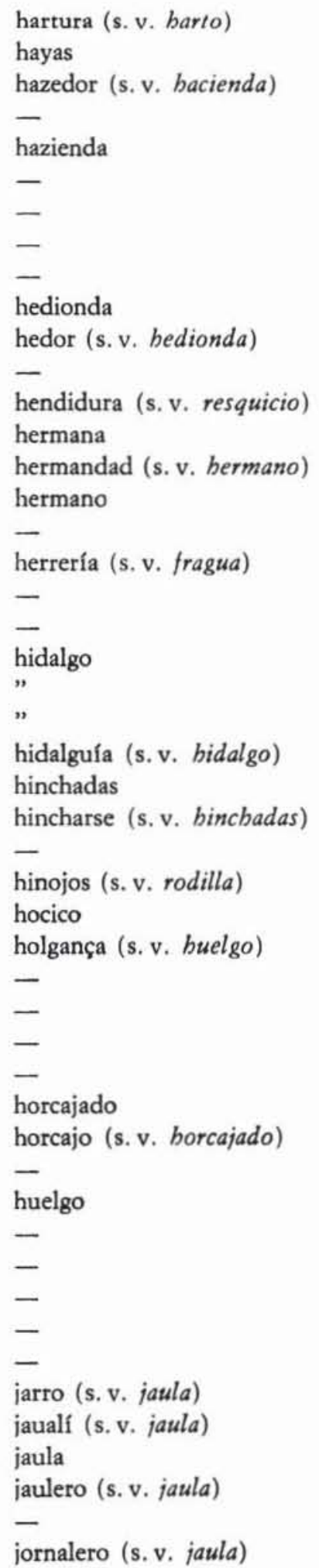




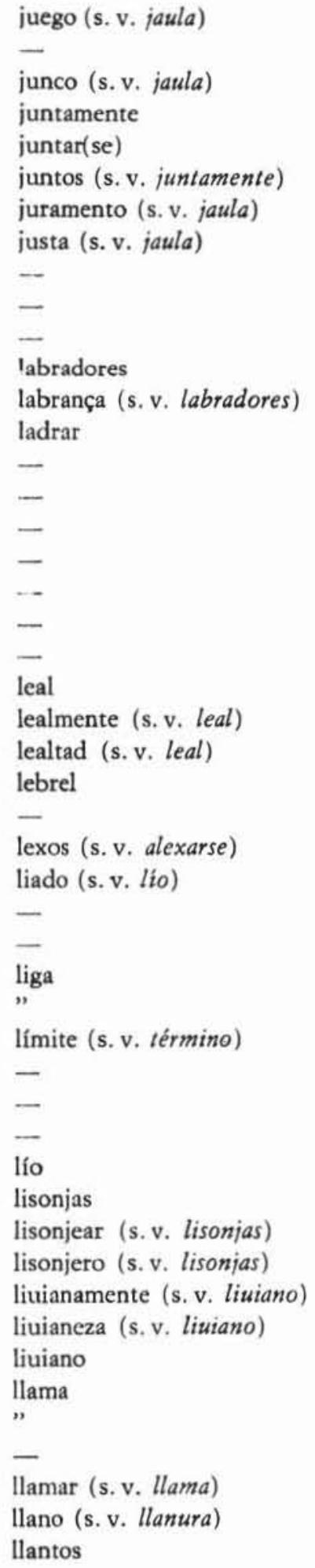

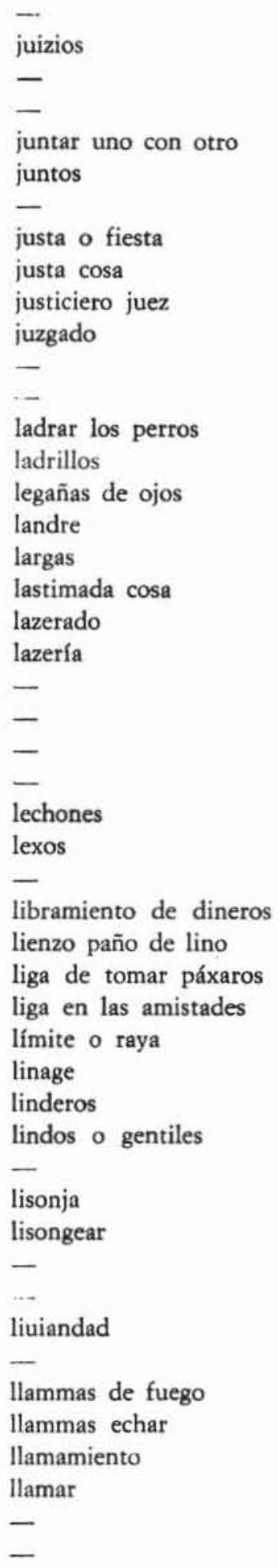


llanura

-

llorar (s.v. Ulantos)

-

-

-

loco

"

$"$

locuras (s. v. loco)

lograr

logrero (s. v. lograr)

logro

-

losas

-

-

machacadura (s.v. machucado)

machucado

machucar (s.v. machucado)

maderar (s. v. maderos)

maderos

-

madrasta

-

majadas

maltractado

-

$-$

mançanar (s.v. mançanas)

mançanas

-

mançano (s.v. mançanas)

manceba (s. v. mancebos)

mancebía (s. v. mancebos)

$"$

mancebos

-

-

$-$

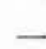

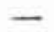

manzilla (s. v. amanzillar y manzillar) llegar aduerbio

lleno o llena cosa

llorar con lágrimas

llouer

llouiznar

loar

lobo

loçano

loco como bouo

loco de atar

loco como quiera

locura assí

-

-

lombrid de estómago

luego aduerbio

luego

luuia [11]

-

-

$-$

-

madexas

madrugar

maguera

-

maña

manar agua

-

mançana

mançanilla flor

-

mancebía o putería

mancebía déste

mancebo

manilla

mansa

manso

manteándose

manteca de uacas

manteca de puerco 


\begin{tabular}{|c|c|}
\hline manzillado (y s. v. amanzillar) & 一 \\
\hline - & marauedí \\
\hline marchita & - \\
\hline marfil & 一 \\
\hline marrano & - \\
\hline - & mas \\
\hline mata & - \\
\hline matadero (s. v. matança) & - \\
\hline matador (s. v. matança) & - \\
\hline matança & - \\
\hline matar (s. v. mata y matança) & - \\
\hline mazmorra & - \\
\hline - & mecer el ojo \\
\hline medianero & - \\
\hline - & medida de la tierra \\
\hline - & medida del mundo \\
\hline- & medida \\
\hline medrosa & - \\
\hline- & mellar alguna cosa \\
\hline - & meneándose \\
\hline - & meneo \\
\hline mengua & - \\
\hline menguado (s.v. mengua) & - \\
\hline menguante (s.v. mengua) & - \\
\hline menguar (s.v. mengua) & - \\
\hline mesnada & - \\
\hline mesón (s. v. mesonero) & mesón \\
\hline mesonero & mesonero \\
\hline messar(se) & - \\
\hline mexillas (s. v. rostro) & - \\
\hline miedo & - \\
\hline- & migaja \\
\hline milano & - \\
\hline - & mimbre o uimbre \\
\hline minique (véase dedo) & - \\
\hline- & misterios \\
\hline mocedad (s. v. moço y mancebos) & mocedad como niñería \\
\hline (véase mancebfa (s. v. mancebos) & mocedad o mancebía \\
\hline mochachos & mochachas \\
\hline moço & moço de cauallos \\
\hline$"$ & moço o mancebo \\
\hline$"$ & moça que sirue \\
\hline$"$ & moça \\
\hline moçuela (s.v. moço) & - \\
\hline mofadura (s.v. motar) & - \\
\hline mofar & - \\
\hline- & mohino \\
\hline mojado & - \\
\hline mojar(se) (s.v. mojado) & - \\
\hline
\end{tabular}




\begin{tabular}{|c|c|}
\hline mojonar (s.v. mojones) & - \\
\hline mojones & - \\
\hline moler (s.v. molido) & - \\
\hline molido & - \\
\hline- & momos hazer \\
\hline montero & - \\
\hline montones & - \\
\hline - & mucho \\
\hline- & mudas de rostro \\
\hline- & muelas de la bocca \\
\hline - & muger \\
\hline- & muñeca parte del braço \\
\hline- & muñeca de niñas \\
\hline murciélago (y s.v. bubos) & murciélago \\
\hline- & murmullo de gentes \\
\hline - & murmurar \\
\hline muslo & muslo de pierna \\
\hline- & nabo \\
\hline nada & nada ninguna cosa \\
\hline nadador (s. v. nada) & - \\
\hline nadar (s.v. nada) & nadar \\
\hline nadie & nadie por ninguno o ninguna \\
\hline - & naranjo \\
\hline- & nariz del hombre \\
\hline- & nauidad \\
\hline neguilla & neguilla simiente \\
\hline - & nesciamente \\
\hline- & nescio \\
\hline nieto & nieto \\
\hline niña & niñas de los ojos \\
\hline$"$ & niños o niñas que aún no hablan \\
\hline niñerfa (s. v. niña) & niñerías de aquestos \\
\hline- & niñez de niños grandezicos \\
\hline - & no se le cueze el pan \\
\hline nouillo & - \\
\hline- & nunca aduerbio \\
\hline- & nunca más perro al molino \\
\hline - & obedecer \\
\hline- & obispo \\
\hline- & offrenda \\
\hline- & offrescer \\
\hline - & ogaño \\
\hline- & oler \\
\hline ollas & - \\
\hline ollero (s. v. ollas) & - \\
\hline- & olor suaue \\
\hline oluidados & - \\
\hline oluidar (s. v. oluidados) & $\cdots$ \\
\hline oluido (s.v. aluidados) & - \\
\hline
\end{tabular}




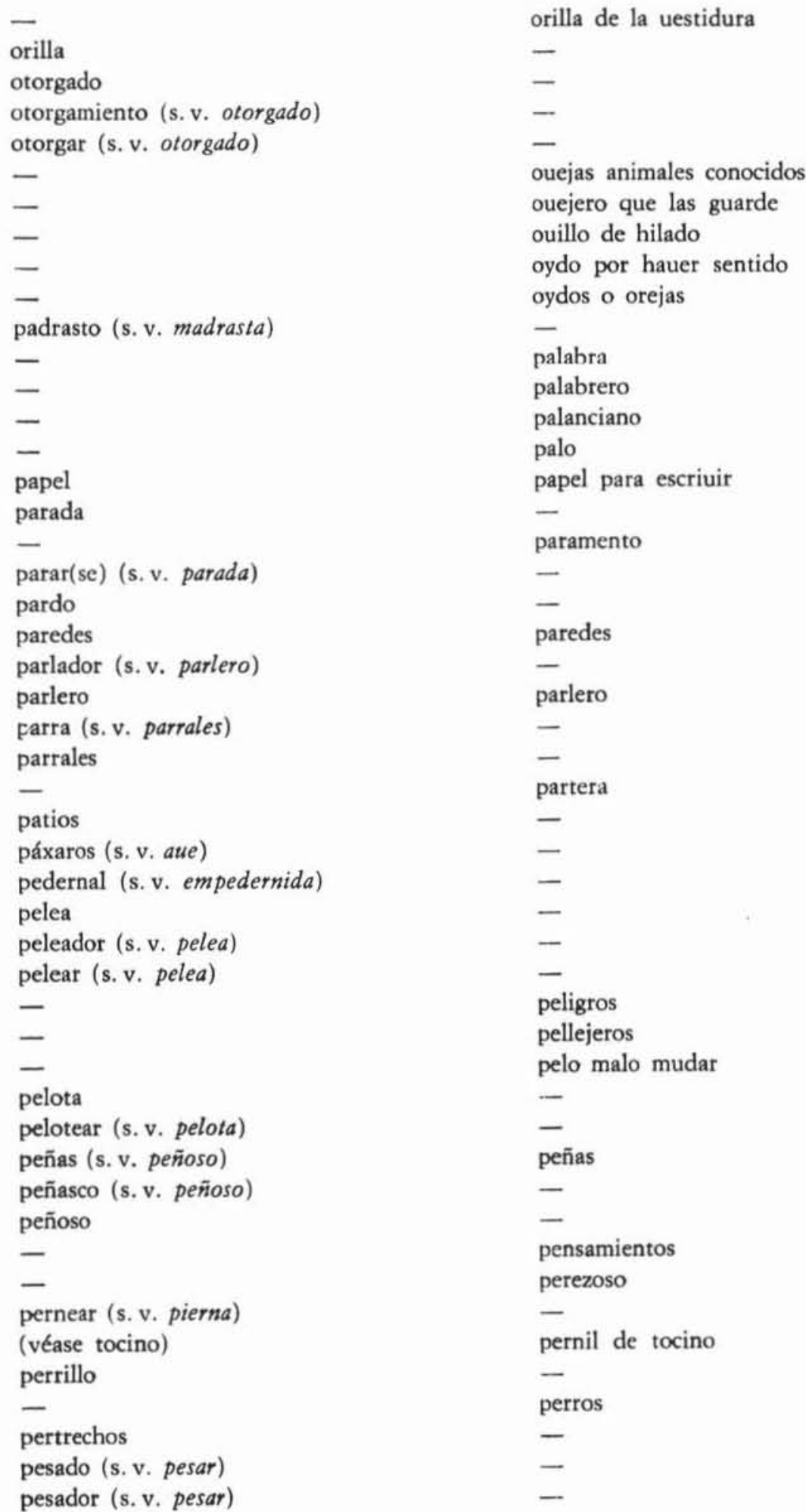

orilla de la uestidura

$-$

ouejas animales conocidos ouejero que las guarde ouillo de hilado oydo por hauer sentido oydos o orejas

-

palabra

palabrero

palanciano

palo

papel para escriuir

-

paramento

-

paredes

-

parlero

-

partera

-

一

-

-

peligros

pellejeros

pelo malo mudar

-

peñas

-

pensamientos

perezoso

pernil de tocino

-

perros 
pesar

pescueço

-

$$
\text { - }
$$

pierna

pilares

pisada (s.v. pisar)

-

pisar

plata (s.v. plateada)

plateada

platear (s.v. plateada)

plateros (s.v. plateada)

pleiteador (s. v. pleitos)

pleitear (s.v. pleitos)

pleitista (s. v. pleitos)

pleitos

podenco

ponçoña

ponçoñar (s. v. ponçoña)

ponçoñoso (s. v. ponçoña)

-

$-$

-

-

-

postes (s. v. pilares)

pregón

pregonar (s. v. pregón)

prenda

prender (s.v. prenda)

$-$

-

$-$

-

-

-

punçadura (s.v. punçón)

punçar (s. v. punçón)

punçón

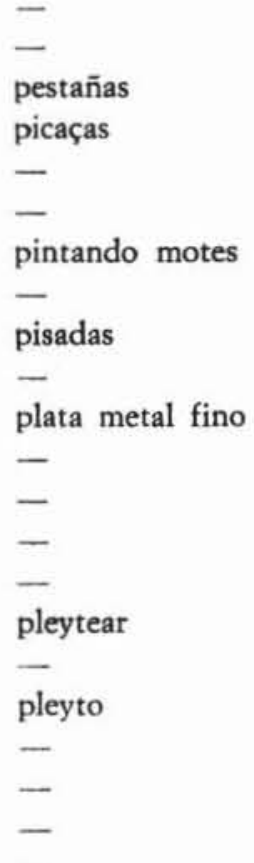

poner la uida al tablero ponerse el sol porende porfía porfiado porradas dar hablando posadas están posadas

-

preñada muger

-

primo hijo de hermano priuado de señor prolixamente prolixidad prouecho prouechosamente prouechoso puerca grande y parida punçadura assí punçadura punçar

purgación de cuerpo 


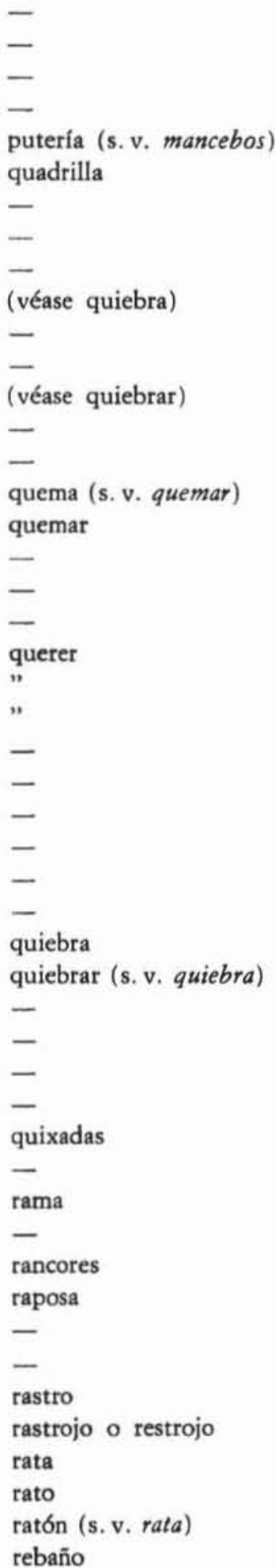

purgación de peccados

puta ramera

puta esta mesma

putañero hombre

-

qualquier beneficio

que no se toman truchas a bragas enxutas quebrantador de fe quebrantar la cárcel quebrantar las paredes de casa agena quebrantamiento de fe quebrar o despedaçar quebrar o quebrantar quebrar la fe

quemarse en el fuego quemarse en el agua callente querella o quexa querencia por amor querer por uoluntad querer bien amando quiero o desseo questión o pregunta interrogancia questión en pleyto o lid questión o ruido de armas quexa quexarse quiçá por ventura

(véase quebrar o despedaçar) quinientos mill quitado quitamiento de casados quitar la honrra quixadas o quixar racionero prelado

ramera o cantonera muger

(véase zorra o raposa)

rasgados ojos

rasgar o romper

rastro de pisada

rastrojo

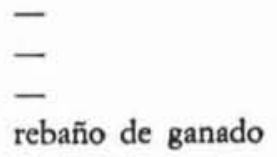




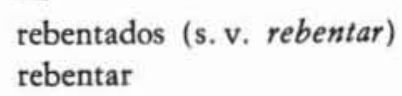

rebatar

rebentados

rebentar sonando

reboçados

reboluedor

reboluer

-

reçongadores

reçongar

refrán o proverbio

refrigerio

-

-

-

reja de hierro para arar reja de uentana

-

renta o patrimonio renteros que la dan

reproches

-

retoçar con la moça retoço con la misma reuesar

rincón río buelto rixoso hombre rocadero rodeo rodeos o largas rodillas de pierna roffián de muger pública rogar roido de gente armada roido de pies pateando roido hazer éstos rollo columna desta forma romadizo 
rumiador (s.v. rumiar)

rumiar

-

-

$-$

sacudir

-

-

$=$

sapo

sartén

-

saya

sayones (s. v. verdugo)

segadores

segurón (s. v. bacha)

-

senzillamente (s.v. sencillo)

senzillez (s.v. senzillo)

senzillo

seso

sesudo (s. v. seso)

sierra

-

-

-

-

-

一

$-$

-

sobradas

sobrar (s. v. sobradas)

--

-

sobrino

soga

soguero (s.v. soga) rumiar el ganado

ruuio

ruyn hombre

sabuessos

sacar fuera

saco o costal

sacudir qualquiera cosa

salir

sana cosa en sí

sanar de enfermedad

sanar a otro

-

sastre

sáuanas

saya de muger

(véase verdugo o sayón)

segadores

segar el trigo

semblante de cara

sentarse a comer

-

-

seso de hombre

sesudo de buen seso

siglo

silla de cauallo

silla de sentar

simplemente assí

simpleza no doblatura

simuladamente

simulador

soberana cosa

soberanamente

soberuia

sobrada cosa

sobre preposición

sobresalto al coraçón

sobrina assí

sobrino hijo de hermano

soga

一

sojuzgadas 


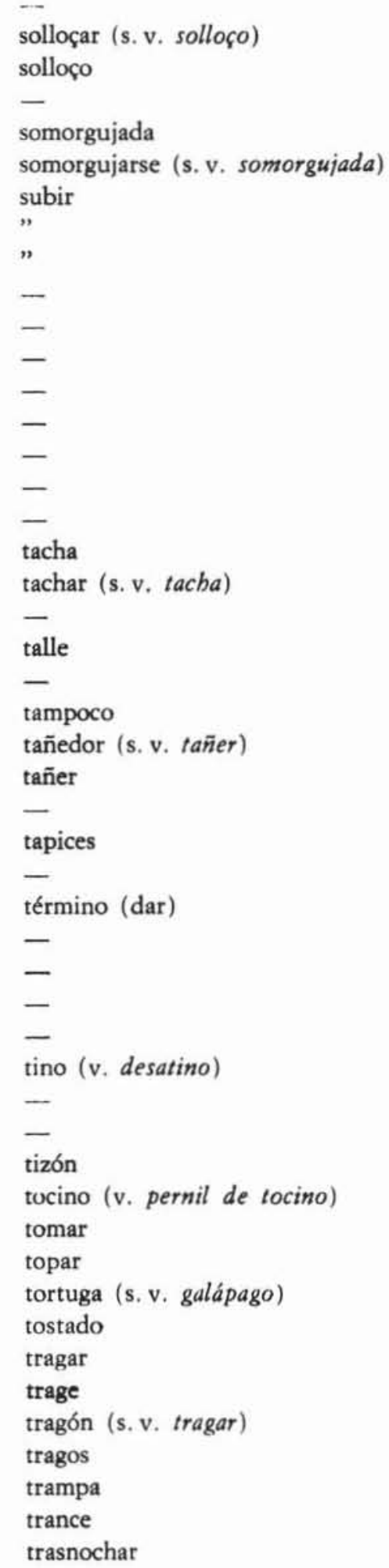

solimán

solloçar

solloço

someterse

$-$

subir sobre alguna cosa

subir a cauallo

subir al cielo

suelta de mula o cauallo

suelto cosa no atada

sueño durmiendo

sueño soñar

suso preposición

suzia cosa

suziedad

tablado

tacha o deffecto

tajada o reuanada de algo

también

tañedor

tañer

tapar algo

tenazas

terrible

testigo

tez lisa

tinaja

tiro aquél que se echa titubar o bambanear

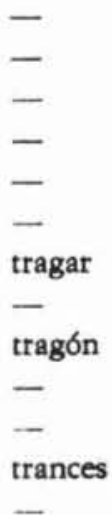




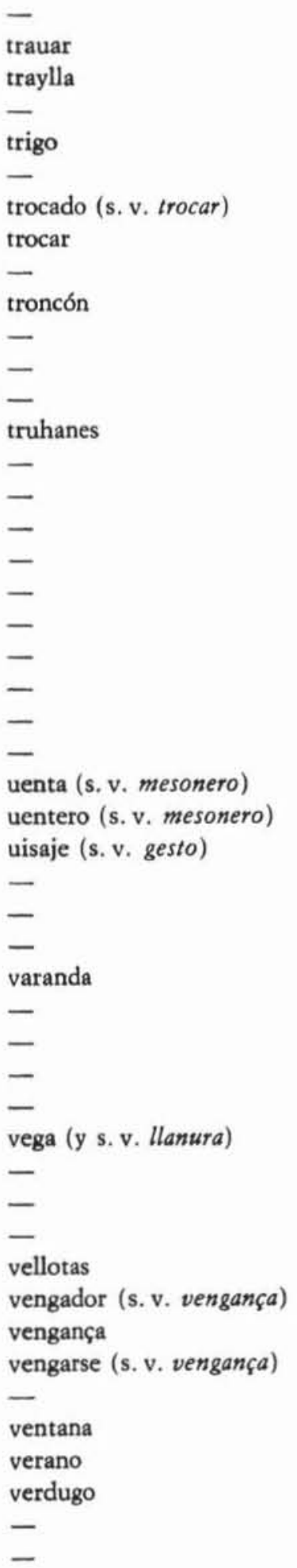

trastócame essas palabras

-

trebol flor

trigo o grano

trobar hazer uersos

-

trompeçar

trota conuentos

troxe de pan

trueco o trueque

truhán ridículo

truhanear

tú dirás lo tuyo entre col y col lechuga

tuerto de un ojo

tuétano

tumbando

tundidor que lo tunde

tundir paño

turma de animal

turnio o uizco del ojo

ubre de muger

venta de campo

ventero que la habita

(véase gesto con visaje)

vado

valle

vallena de mar

-

vasquear con la muerte

vayna de spada

vaziar

vazío

-

vela de noche

vela de naue

vela candela

-

-

venta en la almoneda
ventana o finiestra
verano
verdugo o sayón
vereda
vergel o jardín



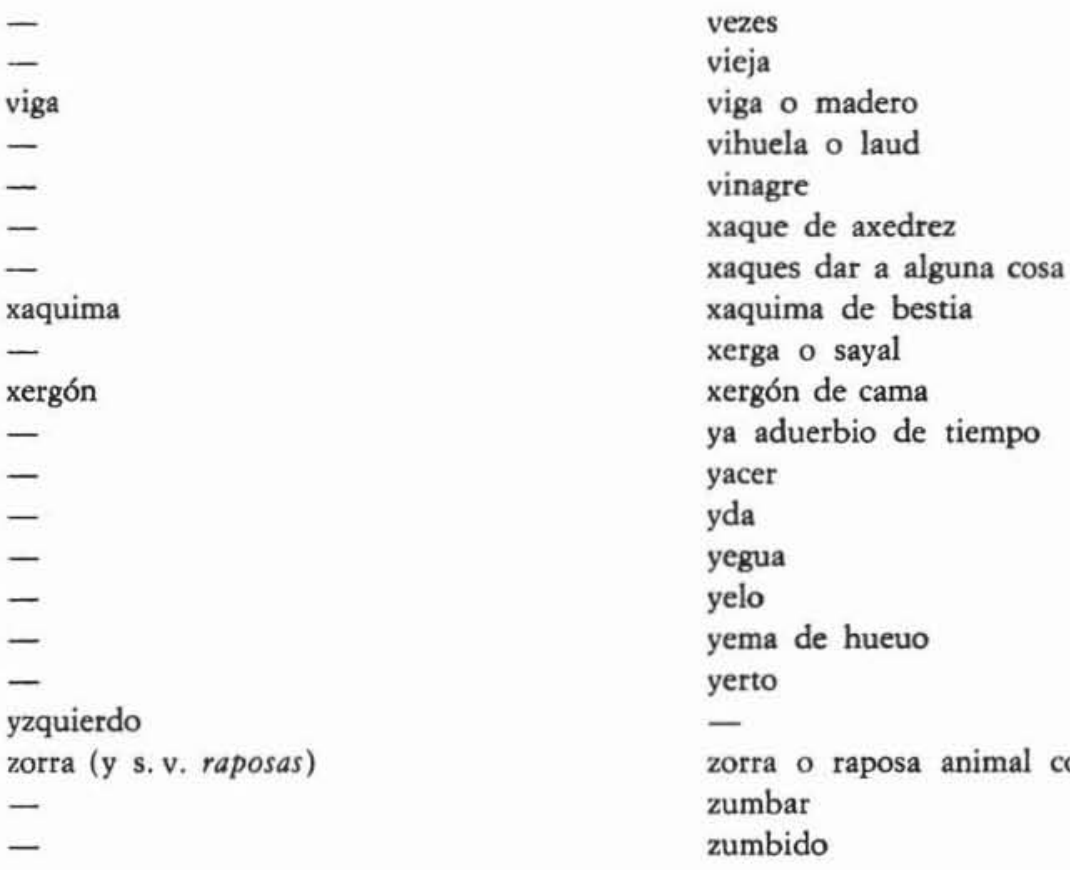